\title{
Pensamiento débil y reforma educativa: la racionalidad bajo el signo de las apariencias
}

\author{
José Beltrán Llavador
}

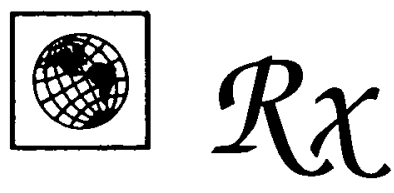

No extrañará el lector que la reflexión (como es éste el caso) llame la atención sobre la ausencia de reflexión. Se argumenta aqui desde documentos y referencias reconocidos que la racionalidad psicológica sobre los medios en la actual Reforma del S.E., ha orillado la racionaliddad filosófica más esencial sobre los fines, llevando asi a un predominio del pensamiento débil y de las apariencias.

\begin{abstract}
«Se vuelve verdad todo lo que todos creen en común. No se pregunta si es el instrumento técnico de la información el que produce este efecto de verdad; se invierte la situación y se dice: "desde siempre la verdad es el acuerdo público de las mentes, la validez intersubjetiva." Lo que creen todos es verdad. „

"El mundo de la técnica moderna es el mundo del "terror pedagógico", que se organiza precisamente mediante las "instituciones". Estas últimas son continuamente "reformadas", a fin de que desempeñen más "racionalmente" su tarea: in-formadas a informar. Si alguien quisiera objetar que, en realidad, las instituciones no funcionan, que precisamente éste es el aspecto más relevante del mundo contemporáneo, su "caoticidad", bay que constestarle que él mira el punto equivocado y de modo "arcaico". Este piensa todavía que las instituciones modernas deben educar y formar almas. En realidad aquéllas deben promocionarse a si mismas, in-formando y domesticando a las almas dentro de su propio proyecto. Y no se puede decir que no lo consigan.*
\end{abstract}

Carlo Sini: Pasar el signo, 372, 376

La presente reflexión se despliega desde un ámbito curricular ausente en nuestra actual Reforma del Sistema Educativo: la fuente o fundamentación filosófica. Esta elección no es arbitraria, antes bien, desde tal orientación este ensayo toma partido y se posiciona en un doble sentido: en primer lugar, pretende relacionar y poner en juego una serie de cuestiones a partir de dos disciplinas diferenciadas: la filosófica y la pedagógica, en contraste con la dinámica o lógica que subyace al actual proceso de reforma en su estrecha alianza con la psicología; en segundo lugar, esta perspectiva permite denunciar la ausencia de un discurso a nuestro parecer necesario para guiar los actuales cambios educativos, a saber, el discurso propio de la racionalidad de los fines, que la planificación de la reforma relega totalmente en favor de una racionalidad de los medios. La hipótesis que recorre este ensayo es que nuestra actual reforma se enmarca (se explica más y por tanto se comprende mejor) dentro de la corriente del llamado "pensamiento débil», que no es sino una nueva per-versión de la modernidad o, si se prefiere, otra versión más de la post-modernidad. Y todo ello 
puede tener una serie de consecuencias o efectos relevantes en el mundo de la vida, algunos de los cuales ya se están materializando, y que podrían formularse como un dominio creciente de las apariencias. Acudiremos a algunos documentos que se han venido generando desde la reforma para ilustrar tales efectos y con el fin de analizar con mayor claridad las determinaciones del «contexto" sobre el "texto" o discurso en boga, así como las implicaciones de éste sobre aquél en una circularidad difícil de romper.

\section{ALGUNOS MARCOS DE ORIENTACION FILOSOFICA}

Como dijimos al principio, el uso de marcos filosóficos para guiar esta reflexión es deliberado, y además de la pertinencia de las nociones que se derivan de los mismos, este uso pretende ilustrar alguna de las ausencias, o de las posibles presencias, en las fuentes del currículum que sustentan nuestra actual reforma del sistema educativo. Ciertamente, la filosofía hace ya tiempo que abandonó su hegemonía como síntesis y como saber rector del resto de las ciencias, pero todavía no se le puede negar su papel concomitante como crítica material y como praxis para una política de la vida. Por eso, apropiándonos del clásico aforismo: "para llegar a un punto desconocido, es preciso tomar un camino desconocido", y reconociendo que aun sin ser del todo desconocido, la filosofía supone en la actualidad un camino menos familiar que el resto, nos gustaría desvelar y clarificar ciertos aspectos cuya plana asunción acaba incorporándolos al caudal de tópicos del que se nutre el sentido común. Para ello, dentro de este discurso filosófico que desde aquí vindicamos en oposición al declive de las razones solidarias (aquellas que reclaman «la presencia de lo universal en el interés particular»), y teniendo en cuenta el debate del momento, hemos seleccionado un segmento que puede dilucidar desde otra perspectiva algunos de los rasgos que caracterizan y que ponen en tela de juicio la racionalidad, o más bien el tipo de racionalidad, que preside nuestra reforma.

\section{Pensamiento débil}

A grandes rasgos, el programa del pensamiento débil, frente a las claves dialécticas, se caracteriza por su intento de socavar las estructuras más sólidas de la metafísica, haciendo ver que éstas «eran sólo los medios con que el pensamiento se tranquilizaba, en épocas en que la técnica y la organización social no nos habían capacitado, al contrario de lo que ocurre hoy, para vivir en un horizonte más abierto, menos garantizado «mágicamente». Los conceptos rectores de la metafísica -la idea de una totalidad del mundo, de un sentido de la historia, de un sujeto centrado en sí mismo y eventualmente capaz de hacerse con ese sentido- se muestran ahora como instrumentos de aleccionamiento y de consolación, ya no necesarios en el marco que la técnica hoy nos proporciona.» (Vattimo, G., 1988: 26-27) Frente a tales conceptos, el pensamiento débil deslegitima a la razón de cualquier función fundamentadora y privilegia los rasgos de la caducidad del ser y de la intuición como instrumento"eminentemente estético»- demostrativo. La función y la forma de la razón quedan reducidas así a un mero «tomar nota» de cuanto sucede. Siguiendo este lineamiento débil, la noción de verdad también sufre una inversión significativa, de manera que su naturaleza ya no es lógica -»lo verdadero no es objeto de una aprehensión noética del tipo de la evidencia»-, sino retórica -resuelta en «el espacio de libertad de las relaciones interpersonales, de las relaciones entre las culturas y las generaciones." En consecuencia, del horizonte retórico de la verdad tan sólo se desprenden verdades «débiles» (Vattimo, G., 1988: 38-39).

Pero la formulación del pensamiento débil habría que situarla como uno de los efectos que acompañan al debate mucho más amplio que está teniendo lugar ahora 
mismo sobre la modernidad. Dentro de esta discusión, que se realiza desde la arena de diferentes disciplinas, el ensayo de Habermas (1988: 32-35) «La modernidad: un proyecto inacabado" constituye una referencia importante para quienes se pronuncian a favor o en contra de la modernidad o de la posmodernidad. (AA.VV., 1988) En tal ensayo, Habermas se posiciona frente al conservadurismo de quienes pretenden dar por liquidado el proyecto de la modernidad, dando por agotadas, de paso, las energías emancipatorias a las que debía su origen y su impulso, y dando por superada la razón -la racionalidad- que alentaba todo su desarrollo. La tematización de la modernidad, además, se entiende mejor en el contexto de la llamada «dialéctica de la Ilustración", una de cuyas últimas formulaciones, por el lado de la posmodernidad, adquiere expresión en el pensamiento débil, y que en otro momento habíamos resumido como sigue (Beltrán, J., 1993): «La dialéctica de la Ilustración, a grosso modo, sostiene la tensión entre una progresiva racionalización (aumento de racionalidad) en las sociedades modernas y su reducción a una mera razón instrumental, que subordina los fines a los medios. Esta dialéctica revela no tanto la debilidad de la razón, sino la extensión de una falsa racionalidad del mundo moderno por la que la idea de razón aparece como ilusoria. Dentro de esta dialéctica, el polo de la condición posmoderna vuelve la espalda al poder explicativo y legitimatorio de los grandes relatos y de las metanarrativas, y así se cuestiona, por ejemplo, la validez que puedan tener los estudios sobre la competencia comunicativa como argumento o marco teórico para proporcionar criterios universalistas. El pensamiento débil, en esta línea, renunciando a todo fundamento, esto es, a toda certeza ontológica, y tirando por la borda el lastre de las determinaciones históricas, tan sólo puede librar algunas verdades débiles. Pero con ello paradójicamente se confía al cumplimiento de su propio destino metafísico que busca su apertura, más allá del callejón sin salida de la modernidad, hacia otros horizontes posmetafísicos.»

\section{Modernidad y reforma educativa}

El fenómeno de la modernidad nos conduce de manera casi inevitable a uno de los procesos más importantes que caracterizan a las sociedades desarrolladas: el de la modernización. Esta noción es una de las traducciones más poderosas en que ha derivado el concepto de modernidad, y su acepción designaría una exigencia de «concreción empírica de la modernidad.» Ahora bien, el proceso de modernización se puede ver realizado de dos maneras antagónicas. La primera de ellas se haría efectiva como proceso reflexivo, aquel que contempla los problemas de las sociedades modernas como derivados de los logros precedentes. Este tipo de modernización sería compleja, negación de la negación, y reclamaría la evaluación constante de los errores del pasado y su proyección en las condicones del presente para su corrección y transformación desde un presente no sólo inmediato, sino que tenga en cuenta las condiciones de posibilidad mediatas o de futuro. El progreso, en este caso, no tendría un caracter lineal y unidireccional, sino que se contemplaría como un programa de ajustes, desplazamientos, iteraciones, avances y retrocesos, que se desarrollaría a partir de determinados criterios de racionalidad, esto es, a partir de «la búsqueda inteligente de fines apropiados» (Rescher, N., 1993: 15). La modernización compleja encontraría en la racionalidad de fines o evaluativa no sólo un desiderátum, sino su plena justificación. Al ejercicio de este tipo de racionalidad se le podría designar, para los propósitos que nos conciernen, "pensamiento fuerte». Contra esta modernización compleja, se alzaría un tipo de modernización simple, gestión de la adaptación, que lejos de cuestionar las premisas de la sociedad industrial, las da por sentadas y erige desde ésta todo su programa de acción, sin otra perspectiva que la que exige la propia inmediatez de su desarrollo lineal y de su expansión creciente. Aquí la racionalidad de fines se vería subvertida por una racionalidad de medios, cuyo despliegue, ante la ausencia de orros intereses que la guien, queda doblegado a las leyes del mercado y 
expuesto al socaire de las voluntades de poder o de dominio, cualesquiera que sean la naturaleza y materialización de éstas. El ejercicio de este tipo de racionalidad se podría identificar sin dificultad con los rasgos con los que quedó esbozado el «pensamiento débil».

No cabe duda que el término «modernización» está conociendo en nuestra historia reciente un uso sin precedentes en los discursos públicos de todo signo. La esfera de lo educativo, en tanto que reflejo del imaginario social, tampoco ha permanecido ajena a este uso desmesurado del término. Y dentro de ella, sin duda, el último momento más significativo y la última "concreción empírica» de la modernidad se encuentran en la actual reforma del sistema educativo. La cuestión que inevitablemente se nos plantea a partir de aquí apunta hacia la pertenencia de nuestra reforma a uno de los dos tipos de modernización tal como han quedado enunciados. Dicho, si se prefiere, de otra manera: ¿Cabe entender nuestra reforma como un caso relevante de modernización compleja o, por el contrario, se puede entender mejor como un ejemplo sustantivo de modernización simple? Si podemos responder afirmativamente a la primera de las alternativas planteadas, entonces sin duda cabe albergar algún tipo de confianza, más allá de toda apariencia de signo contrario, en la presencia significativa de una racionalidad de fines subyacente no sólo en la reforma, sino en los contextos en los que ésta encuentra su origen y reflejo. Si, en cambio, tenemos que responder afirmativamente a la segunda de las alternativas planteadas, entonces se verían confirmadas nuestras sospechas, más allá de toda apariencia de signo contrario, hacia la fragilidad del tipo de racionalidad subyacente tanto en la reforma como en los contextos que la explican y la determinan.

\section{LA AUSENCIA DE FINES}

Para dar respuesta a nuestras preguntas, quizá convenga prestar cierta atención a la justificación teórica sobre la que se asienta nuestra actual reforma educativa, esto es, a las así llamadas «fuentes curriculares». Estas constituyen los factores que fundamentan un currículum desde diferentes enfoques con el fin de dotarlo de legitimidad. Esta reforma, a través del Diseño Curricular Base (DCB), ha seleccionado cuatro fuentes que a su vez refieren a una serie de disciplinas, que en este caso son: la psicológica, la sociológica, la pedagógica y la epistemológica. A partir de estas cuatro áreas «el currículo trata de dar respuesta a algunas preguntas fundamentales: qué enseñar, cuándo enseñar, cómo enseñar, e igualmente, qué, cuándo y cómo evaluar. Tal respuesta se concreta a partir de fuentes de naturaleza y origen diferente.» (DCB, 1989: 22) Ahora bien, y es ésta una queja ya formulada (Salinas, D, 1992: 16; Beltrán, J, 1993), si alguna pregunta fundamental brilla por su ausencia entre aquellas a las que el DCB trata de dar respuesta, es la siguiente: para qué enseñar o por qué enseñar, es decir, aquella que nos remite al ámbito de las razones y de los fines, al espacio propio de la racionalidad emancipatoria y evaluativa. Ignorar en el debate y en la construcción de la reforma la cuestión referida a sus propios fines ilustra de manera poderosamente significativa que la racionalidad que la rige es de carácter puramente instrumental, primando los medios sobre las metas, la técnica sobre los propósitos, y disfrazando la ideología como tecnología. Esta «apatía», en el sentido de ausencia de "pathos", de sentido o de sendero, se suple con la mera inercia, y acaba desembocando en un «semanticidio» o vacío racional: la maquinaria se desliza sola arrastrada por su propio peso, y atraida por las metas que se le asignan externamente. El no formular de manera expresa esta pregunta, lógicamente anterior a las demás, quizá pudiera ofrecer la apariencia de una intencional neutralidad ideológica o de un pretendido objetivismo. Pero, apenas levantemos el velo de tal apariencia, descubriremos que el hecho de no hacer abiertamente explícito «por qué enseñar nos muestra las formas vigentes más marcadamente ideológicas de «por qué» enseñar. Así pues, una empresa de las dimensiones de nuestra reforma que olvida esta 
pregunta, deliberadamente o en una muestra de injustificada ceguera, puede acabar convertida en un programa de contenido no ya austero, sino precario, de «mucho ruido y pocas nueces", debilitando cualquier linea de argumentación que se desprenda de su ambigua retórica, y consintiendo, en cambio, con la lógica «tecno-lógica" de la eficacia, de la eficiencia, de la cantidad traducida en cálculo egoista cuando no en usura; la misma lógica, justamente, que domina con inercia arrolladora nuestras sociedades. De esta manera también, y pidiendo prestada la metáfora de Wittgenstein, cuando cierto lenguaje conceptual «se va de vacaciones», dando entrada en cambio a la más sonora quincalla terminológica, «el ruido que se provoca en aspectos técnicos sirve en muchos casos para justificar debilidades o encubrir propuestas en las funciones externas.» (Gimeno, J., 1993: 64) Quizá estos primeros apuntes proporcionen de momento algunos elementos para ir dando respuesta a la pregunta por la reforma como nueva forma de modernización simple o compleja.

\section{EL ORDEN DEL DISCURSO O LOS MOTIVOS DE LA LOGSE}

Pero si hemos comenzado con el texto que justifica y enmarca la reforma, que en buena medida la describe dándole su formato, nos remitiremos a continuación al texto que la prescribe, proporcionándole su concreción normativa y su «forma jurídica»: La Ley Orgánica de Ordenación General del Sistema Educativo, más conocida como LOGSE, que «se convierte en el elemento esencial de la reforma». La filosofía que un año antes había quedado recogida en el Libro Blanco para la Reforma del Sistema Educativo (1989) -como veinte años antes hiciera el Libro Blanco preludiando la Ley Villar Palasí-, encuentra ahora su reflejo y su compendio en la «exposición de motivos» con la que se inicia la LOGSE.

Una primera lectura a esta declaración de intenciones y de intereses ya nos permite entender mejor, aunque nunca justificar bastante, la ausencia de la pregunta acerca de los fines de la educación que nos llamaba la atención en el DCB. Y es que, cuando en la LOGSE se mencionan y enumeran los fines de la educación, es totalmente transparente al mostrar que la escuela carece de otros fines que aquellos que el propio contexto le asigna. Veamos un primer ejemplo, extraído de los primeros párrafos de la Ley: «El objetivo primero y fundamental de la educación es el de proporcionar a los niños y a las niñas, a los jóvenes de uno y otro sexo, una formación plena que les permita conformar su propia y esencial identidad, así como una concepción de la realidad que integre, a la vez, el conocimiento y la valoración ética y moral de la misma. Tal formación plena ha de ir dirigida al desarrollo de su capacidad para ejercer, de manera crítica y en una sociedad axiológicamente plural, la libertad, la tolerancia y la solidaridad.» Si nos detuviéramos aquí, apenas tendríamos nada que observar. Pero si avanzamos unos cuantos párrafos más, apreciaremos que la concreción de «los fines que orientarán el sistema educativo español» ha adquirido nuevos matices que no conviene pasar por alto: «en esa sociedad del futuro, configurada progresivamente como una sociedad del saber, la educación compartirá con otras instancias sociales la transmisión de información y de conocimientos, pero adquirirá aún mayor relevancia su capacidad para ordenarlos críticamente, para darles un sentido personal y moral, para generar actitudes y hábitos individuales y colectivos, para desarrollar aptitudes, para preservar en su esencia adaptándolos a las situaciones emergentes, los valores con los que nos identificamos individual y colectivamente.» (la cursiva es nuestra) Cuando aquí se declara que «la educación compartirá con otras instancias sociales» la función de transmisión de conocimientos, en realidad se está señalando, de manera encubierta, la dependencia o subsidiariedad de aquélla respecto de éstas. Es esta subordinación la que finalmente convierte a la esfera educativa en una instancia vulnerable, y a la escuela en «una institución débil». Efectivamente, «otras instituciones como los ejércitos, las empresas o las iglesias forman sus propios objetivos y logran que la sociedad los respete como tales e incluso 
que se asocie a ellos. La escuela, en cambio, no lo consigue o ni siquiera lo intenta. La institución es débil y su discurso también lo es." (Enguita, M., 1990: 97) No se trata, entonces o tanto, de que la educación carezca de fines, como de qué naturaleza son los fines que se le encomiendan desde diferentes instancias y que pueden hacer de la escuela un puro medio, un instrumento o herramienta adecuada a las urgencias del entorno y del momento, inviertiendo así de manera radical la relación de fines y medios. Al respecto, quizá nada resulte tan evidente, como el peso y el énfasis que recibe a lo largo del texto examinado, inclinando la balanza del clásico dilema, el platillo de la adaptación en proporción con la ligereza del de la transformación. Por eso, la cuestión por los fines de la educación -desde la propia educación, pero también más allá de ésta- parece hoy más necesaria que nunca, sabiendo que desborda los marcos desde los que surge para apuntar hacia los nuevos órdenes del discurso dominante. En este caso, la pregunta «fuerte» frente al pensamiento «débil» exige una vez más un planteamiento tan poco novedoso como igualmente radical, dirigido a recuperar para el terreno de la racionalidad evaluativa lo que nunca debió ser confundido y alienado o apartado de su lugar de pertenencia, esto es, la relación original de fines y medios. «En general, los instrumentos sirven inicialmente para satisfacer necesidades; después, las necesidades sirven para poseeer y para usar los instrumentos; y cuando el sistema de necesidades obstruye de cualquier forma el sistema de los instrumentos, es el primer sistema, no el segundo el que se modifica." (Severino, 1991b: 63) Leémos en la LOGSE: «Esta misma necesidad de adaptación se ha dejado sentir con fuerza en nuestro país y la sociedad española en su conjunto (...) se ha pronunciado favorablemente por la reforma en profundidad de nuestro sistema educativo.» $\mathrm{Si}$, como parece, la educación es producto y reflejo a la vez, actúando como mediación subvertida de fines y medios, de los órdenes del discurso, es decir, del con-texto o con-textos dominantes, cabe interrogarnos ahora: ¿A qué nuevos órdenes nos estamos refiriendo? ¿Y a qué tipo de servidumbres nos somete el objeto conceptualizado? A modo de ilustración, seleccionaremos dos tipos de órdenes recurrentes en la reforma: el orden u horizonte europeo, y el orden o la trama de los consensos.

a) El borizonte europeo: El proceso de modernización de España, tan largamente anhelado, se vio formalmente cumplido al alcanzar «su plena integración en las Comunidades Europeas». El norte que guía nuestros destinos se halla fijado ahora en el corazón de Europa. Alfa y omega, las referencias a la dimensión europea abren y cierran las reflexiones que guían los motivos de la LOGSE. De esta manera, el círculo legitimatorio amplía su espectro imponiendo nuevas exigencias, puesto que «la nuestra es una sociedad en acelerado proceso de modernización, que camina, cada vez más nítidamente, hacia un horizonte común para Europa.» Dejando aparte la nitidez u opacidad del proceso, así como la velocidad de primera o de segunda en el ritmo del mismo, lo cierto es que la integración de España en la CEE, cautivada por el canto de sirenas de esa «Europa de los mercaderes», ya ocupa su lugar de importancia en el curriculum escolar, reforzando la imagen de una España plenamente moderna, una vez incorporada al tren de alta velocidad de la competitividad europea. La noción de competitividad es el término reciclado para designar, con más brío y agresividad, lo que hasta hace bien poco se había llamado desarrollo. Otra cuestión, incómoda donde las haya y que aquí tan sólo vamos a rozar, es la hipotética identidad y unicidad del proyecto europeo hacia el que se tiende1: porque cada vez se nos hace más dificil distinguir si estamos hablando con Mr. Jekyll o con Mr. Hyde, es decir, si estamos abriendo un auténtico diálogo con quienes detentan los "valores» ilustrados o si estamos alcanzando acuerdos con el club de los hacendados preocupados en salvar el SME (versión sociológica del dictum positivista: salvar las apariencias) mientras se van amontonando cadáveres en algún armario de la casa común. A pesar de lo descarnado de esta caricatura, este cuadro podría tener cabida en el paisaje que Severino preconiza para el devenir de Occidente en lo que plásticamente califica «el paraíso del Aparato». (Severino, E., 1991b: 81-89) Contra quienes, desde la cultura de la satisfacción y despreciando cualquier posibilidad de alter- 
nativa social y política, defienden el fin de la Historia, se podría argumentar que quizá el juego de la Historia (Axelos, K., 1980) no se halla más que en sus inicios como parece desprenderse del caso de Europa. A las puertas del siglo XXI, el rapto de Europa todavía no se ha resuelto y son muchos los dioses que codician su posesión.

b) La trama de los consensos: En la actualidad parece haber calado hondo un consenso sobre el consenso, de suerte que buena parte de las actuaciones y de los enunciados que las justifican, y que quieran encontrar un refrendo social, lo harán apelando a los acuerdos intersubjetivos o en base a consensos alcanzados. Es un hecho que «las democracias reales han tendido a la eliminación de las tensiones y conflictos que las constituyen. Han enfatizado el pacto y el consenso. Lo mismo sus teorizadores (Habermas ha construido toda una metafísica del consenso sobre estas bases; una empresa que se me antoja perfectamente estéril y prescindible.» (Trías, E. y Argullol, R., 1992: 33) No es extraño, pues, que también en la LOGSE este fenómeno encuentre su reflejo: «El convencimiento de que en una reforma de este tipo (...) no se podrían cosechar todos sus frutos más que apoyándose en un amplio consenso, aconsejaba, en fin, que se propiciara el mayor debate posible acerca de la misma, tratando de construir sobre éste un acuerdo esencial y duradero sobre sus objetivos fundamentales.» Sin embargo, continuando con la primera cita, "la ficción de esa democracia real basada en el consenso, su mentira, su carencia de verdad democrática se deriva del hecho de que no cubre, ni con mucho, las aspiraciones de un porcentaje grande y relevante de la población. En efecto, un amplio sector no vota.» (Trías, E. y Argullol, R., 1992: 33) Pese a la anterior declaración de la Ley, habrá que admitir que una de las críticas más generalizadas y más «razonables» (cargadas de racionalidad) que ha recibido la reforma por parte de la comunidad educativa y de los agentes sociales ha sido precisamente la que señala el insuficiente margen de participación y debate que ésta ha generado para su diseño y construcción. Así, la apelación al consenso, aun con ser en ocasiones necesaria, cuando se utiliza como procedimiento reiterado y excluyente puede sufrir el efecto perverso de convertirse en una especie de invocación mágica por la que todo parece encontrar solución al revestirse de un engranaje o ritual democrático, eximiéndonos de otra responsabilidad que no sea la del consentimiento mínimo para lograr el acuerdo necesario cuando se nos reclame y si se nos reclama. Pero si destapamos la caja de Pandora del consenso, veremos resurgir aquellos problemos que, lejos de estar resueltos, tan sólo habían quedado disueltos o disfrazados, junto aquellas contradicciones que tampoco habían quedado superadas, sino ocultadas, para cumplir el propósito de salvar, una vez más, el dominio creciente de las apariencias. Por ello, «aun reconociendo ideales positivos en el lenguaje de las reformas, y admitiendo que, como ocurre en nuestro caso, se incorporan declaraciones de principios con los que es fácil estar de acuerdo, es difícil apreciarles en muchos casos méritos más allá de estimular el consenso en torno a ciertos ideales.» Es ésta una idea que otorga el poder del cambio a la fuerza de su discurso. Pero, «en el fondo, es una concepción de la innovación que resulta poco costosa, requiere pocos medios, más allá de difundir la retórica; parece fácil y relativamente rápida. En el mejor de los casos esa política de transformación educativa podría generar un cierto consenso en torno a unas ideas-fuerza, lo que no deja de ser importante, pero de esa táctica no se deduce el cambio de la realidad.» (Gimeno, J., 1993: 63) Sin embargo, la estrategia del consenso está alcanzando tal importancia que, desde los más diversos frentes la convierten en signo de identidad, y así, la pedagogía crítica, los planteamientos humanistas, las reformas neoliberales acaban por apelar a su uso y propiedad, en su afán por despuntar y como un signo de distinción en el ruedo democrático. En este panorama, no tardará el momento en que hasta los «salvajes», "cuando los hayamos educado, como decía Fichte, convendrán con nosotros (si aún están vivos) que es verdad lo que la opinión pública piensa que es verdad.» (Sini, C., 1989: 372) No importa tanto lo que la verdad sea, como la apariencia de verdad. Y ciertamente, la lógica del consenso es consecuente con la inversión de fines y medios 
que antes habíamos señalado: esta «publicidad de la razón» provoca la suplantación del conocimiento colectivo (episteme) por la opinión pública (doxa), de la reflexión participativa por la convención ideológica. La verdad como consenso acaba así convertida en un nuevo objeto de producción (y por tanto, de destrucción), en un bien de uso y cambio, sometida a la especulación, a las alzas y bajas del sistema de necesidades. El uso espúreo del consenso, en fin, acaba transformándolo en un nuevo instrumento, esto es, una tecnología, una nueva y más eficaz figura encubierta de la ideología.

\section{PENSAR «FUERTE»}

Si antes habíamos señalado respecto al lenguaje de las reformas un cierto «semanticidio» por el que determinados conceptos se vacían de contenido, ahora podríamos hablar, utilizando un nuevo símil, de una operación quirúrgica de «logotomía” por la que la racionalidad de fines o emancipatoria queda reducida a sus mínimas constantes. Frente a ese idealismo comunicativo, al que no escapa nuestra reforma, deberíamos comenzar a crear las condiciones para una cultura de la pregunta, de la duda razonable, con el fin de propiciar una auténtica participación como acción no sólo comunicativa, sino también, y sobre todo, transformativa. Avanzar en la búsqueda inteligente de fines, más allá de la ilusión o apariencia de verdad de los acuerdos, supone la evaluación de nuestros discursos y de sus implicaciones en la esfera de las acciones; exige, por tanto, no quedar convencidos por los discursos que hoy se están privilegiando sin haberlos sometido al juicio crítico que dictamine el tribunal de la razón. Pero ello pasa, muchas veces desde el disenso y la resistencia activa antes que desde el consenso o negociación de acuerdos, por la conquista progresiva de espacios de reflexión participativa así como de participación reflexiva. No quiera verse aquí un rechazo a las actitudes de diálogo y al logro de acuerdos como valores democráticos. Más bien al contrario, nos gustaría hacer de ellos vehículos para establecer propósitos adecuados. Pero, como en el mito de la caverna, cuando se entroniza el diálogo hasta convertirlo en un fin en sí mismo, la búsqueda y la construcción de la verdad se convierte en un asunto de opinión, las sombras se toman por las auténticas figuras de la realidad, y el conocimiento se debilita hasta el punto de creer ingenuamente que es un tema de conversación. La primacía desmesurada de las formas actuales de diálogo -su burda traducción en pactos, acuerdos, negociaciones, consensos- puede suponer el enmascaramiento por parte del pensamiento débil de aquello que tuvo su origen más noble y más genuino en el pensamiento fuerte, esto es, la dialéctica. En el corazón de la dialéctica, o del diálogo como indagación auténtica del sentido de las cosas, aguarda viva esa «memoria» del logos, que desde nuestra alienación y nuestra amnesia nos resistimos a recobrar.

Nuestra reforma educativa puede convertirse en una ocasión nada despreciable para repensar, más allá de todo reduccionismo posmoderno, el lugar de la educación en el contexto actual así como nuestro papel como educadores. También puede ser una oportunidad para mostrar nuestra capacidad de resistencia frente a un pensamiento débil que, apelando a la astucia de la razón, tan sólo precisa de nosotros compromisos débiles. Como educadores, todavía no del todo con-vencidos por el sentido común («con-senso») de la retórica dominante, tenemos el derecho toda vez que la responsabilidad de pensar fuerte, apelando a la inteligencia de la razón, exigiéndonos a nosotros mismos, frente a otras voluntades, compromisos fuertes.

Estas páginas han constatado, en la esfera educativa de la que nos hemos ocupado, una debilidad del pensamiento, si no una clara derrota. Pero es esta misma racionalidad la que nos ha dado al mismo tiempo razones suficientes y necesarias para arremeter contra esos castillos de arena del sentido común que nos ocultan otros posibles y deseables horizontes, más allá del estrecho cerco que dibuja la hegemonía de la apariencia. No tenemos más remedio que aceptar, con Rescher (1993: 250), 
que «es un hecho profundamente irónico que la confianza aseguradora en la eficacia de la razón requiera un acto de fe.» Pero en estos tiempos de penuria económica y moral, sería un lujo que no podemos permitirnos el hecho de dejar de creer, a pesar de todo, en la capacidad y en la autoconfianza de la razón para alcanzar su propia emancipación. Para concluir con lo que a lo largo de estas páginas ha acabado por convertirse en un ejercicio escéptico contra el escepticismo, quizá convenga recordar las siguientes palabras de Santayana (1905: 176): «La razón goza de la indomable persistencia de todas las tendencias naturales; vuelve una y otra vez al ataque tal y como las olas chocan en la costa. Observar su derrota es darle ya una nueva encarnación.»

\section{Notas}

1 Tal es la pregunta con la que Severino inicia su reflexión:» ¿Qué es Europa?», y parte de cuya desencantada respuesta no podemos dejar de citar: «Así como la unificación del saber científico es una yuxtaposición de mundos, también la unificación polícica de Europa y en general de toda acción política no puede ser sino una yuxtaposición de objetivos (...). En esta situación es inevitable que las muchas europas luchen entre sí y que acabe prevaleciendo la Europa más fuerte, es decir, la Europa económica-o sea, lo que Europa es desde el punto de vista de la economía política- y que acabemos convenciéndonos de que el motivo más válido para realizar la unificación política de nuestro continente lo dé la organización capitalista de la producción industrial europea, que para competir con la gran industria internacional tiene necesidad de liberarse de los vínculos -constituidos justamente por el orden tradicional de los Estados europeos- que impiden ese aumento indefinido de la producción y esa consiguiente extensión ilimitada del mercado exigidos por la lógica del capitalismo. La yuxtaposición de los objetivos políticos determina la unilateralidad de la acción política; y los objetivos más débiles se convierten en un contorno extrínseco del objetivo económico, más fuerte. De ahí deriva ese tipo de eclecticismo político, tan difundido en el mundo occidencal, que se propone mantener, en torno al núcleo de la economía, los así llamados «valores» de la civilización europea». (Severino, E., 1991 a: Esencia del nibilismo. Madrid: Taurus, 16-17).

\section{Referencias}

AA.VV. (1988). Habermas y la modernidad. Madrid, Cátedra.

ARGULlol, R., y TRIAs, E. (1992). El cansancio de Occidente, Barcelona, Destino.

AxELOS, K. (1980). «La cuestión del fin de la Historia» (1971), en Horizontes del mundo. México, FCE, $111-143$.

Beltran Llavador, J. (1989). El sueño de la alfabetización. Valencia, Consellería de Cultura, Educació i Ciència.

BELTRAN LLAVADOR, J. (1993). «Educación de personas adultas y emancipación social: apuntes para reconstruir un discurso secuestrado.» Educación y sociedad, 12, pendiente de publicación (aceptado).

ENGUITA, M. F. (1990). Juntos pero no revueltos. Ensayos entorno a la reforma de la educación. Madrid, Visor.

Gimeno SaCristan, J. (1993). «Reformas educativas. Utopía, retórica y práctica.» Cuadernos de Pedagogia, 209, 62-68.

Habermas, J. (1988). Ensayos polititicos. Barcelona, Península.

JAMESON, F. (1991). El postmodernismo o la lógica cultural del capitalismo avanzado. Barcelona, Paidós.

Ley Orgánica de ordenación General del Sistema Educativo. (1990)

RESCHER, N. (1993). La racionalidad. Una indagación filosófica sobre la naturaleza y la justificación de la razón. Madrid, Tecnos.

RORTY, R. (1983). La filosofia y el espejo de la naturaleza. Madrid, Cátedra.

SALINAS F., D. (1992). "¿Fuente sociológica o función social del currículum?» Cuadernos de Pedagogía, $190,15-18$.

Santayana, G. (1905-1906). The Life of Reason: Or, The Phases of Human Progress. Nueva York, Scribners; Londres, Constable, 5 vols. The Life of Reason, vol. 1.

SEVERINO, E. (1991a). Esencia del nibilismo. Madrid, Taurus.

SEVERINO, E. (1991b). La filosofía futura. Barcelona, Ariel.

SINI, C. (1989). Pasar el signo, Madrid, Mondadori.

Vattrmo. G., y Rovatti, P. A., eds. (1988). El pensamiento débil. Madrid, Cátedra. 
Pensamiento débil y reforma educativa: la racionalidad bajo el signo de las apariencias José Beltrán Llavador CL\&E, 1994, 21, pp. 43-52

Resumen: La presente reflexión se despliega desde un ámbito curricular ausente en nuestra actual Reforma del Sistema Educativo: la fuente o fundamentación filosófica. Esta elección no es arbitraria, antes bien, desde tal orientación este ensayo toma partido y se posiciona en un doble sentido: en primer lugar, pretende relacionar y poner en juego una serie de cuestiones a partir de dos disciplinas diferenciadas: la filosófica y la pedagógica, en contraste con la dinámica o lógica que subyace al actual proceso de reforma en su estrecha alianza con la psicología; en segundo lugar, esta perspectiva permite denunciar la ausencia de un discurso a nuestro parecer necesario para guiar los actuales cambios educativos, a saber, el discurso propio de la racionalidad de los fines, que la planificación de la reforma relega totalmente en favor de una racionalidad de los medios. La hipótesis que recorre este ensayo es que nuestra actual reforma se enmarca (se explica más y por tanto se comprende mejor) dentro de la corriente del llamado «pensamiento débil», que no es sino una nueva per-versión de la modernidad o, si se prefiere, otra versión más de la post-modernidad. Y todo ello puede tener una serie de consecuencias o efectos relevantes en el mundo de la vida, algunos de los cuales ya se están materializando, y que podrían formularse como un dominio creciente de las apariencias. Acudiremos a algunos documentos que se han venido generando desde la reforma para ilustrar tales efectos y con el fin de analizar con mayor claridad las determinaciones del «contexto" sobre el «texto" o discurso en boga, así como las implicaciones de éste sobre aquél en una circularidad difícil de romper.

Agradecimientos: Este artículo fue presentado como comunicación en el Congreso Internacional de Didáctica (CID) «Volver a pensar la educación» celebrado en La Coruña los días 27 a 30 de septiembre de 1993.

Dirección: Departament de Sociologia i Antropologia Social. Universitat de Valencia (Studi General). Facultad de Ciencias Económicas y empresariales. Avda. Blasco Ibáñez, 30. 46010 Valencia.

Datos del autor: José Beltrán Llavador, doctor en filosofía y maestro de profesión en la modalidad de educación de adultos, ha publicado diversos libros sobre el tema de la alfabetización así como artículos sobre este tema en particular y sobre la educación de adultos en general. Actualmente desempeña el cargo de asesor pedagógico en el Centro de Profesores (CEP) de Valencia y es profesor asociado en el Departamento de Sociología y Antropología Social de la Universidad de Valencia.

(C) PERMISOS PARA CITAR O REPRODUCIR EN OTRAS FUENTES: Se pueden citar libremente hasta 500 palabras. Para reproducir una porción de texto mayor, figuras o ilustraciones, se deberá pedir permiso por escrito a la revista, especificando el uso al que se destina el texto. En todos los casos, se deberá citar el copyright de $C L \& E$. En el caso de artículos o textos que hayn sido a su vez reproducidos en $C L \& E$ los interesados deberán dirigirse tanto a los detentadores del copyright original como a $C L \& E$, en el caso de que se quiera hacer uso de la traducción. FOTOCOPIAS: Para todo lo relacionado con el uso mediante fotocopia del material de esta revista, deberán dirigirse a: CEDRO, C/ José Marañón, 10, $3 .^{\circ}$ Izda. Tel. 594 15 75. Fax 4453567 